\title{
IFN $\gamma$ and B7-H1 in the immunology of mesenchymal stem cells
}

\author{
Pranela Rameshwar ${ }^{1}$ \\ ${ }^{1}$ UMDNJ-New Jersey Medical School, MSB, Rm. E-579, 185 South Orange Ave, Newark, NJ 07103, USA. \\ Correspondence: rameshwa@umdnj.edu \\ Cell Research (2008) 18:805-806. doi: 10.1038/cr.2008.90; published online 4 August 2008
}

Mesenchymal stem cells (MSCs) are found in multiple organs in the fetus, cord blood and adult tissues [1]. However, in adults, the bone marrow is the major source of these stem cells. MSCs surround the blood vessels of bone marrow and are also in contact with the trabeculae [2]. The immunology of MSCs is relevant to medicine. In bone marrow, MSCs could be considered 'gate-keeper' cells. This designation is mostly due to its location in the abluminal surface of the main sinus, which forms the interface between the periphery and marrow cavity $[2,3]$. Cells or organisms entering or exiting the marrow need to by-pass MSCs. The immune properties of MSCs suggest that these stem cells are not bystander cells, but perhaps, they are actively involved in homeostasis of bone marrow.

MSCs function as phagocytes and as antigen presenting cells (APC) [4]. However, the latter function depends on the surrounding levels of IFN $\gamma$ [5]. Previous studies have shown high levels of IFN $\gamma$ mediate decreased expression of MHC-II on MSCs [5]. At high levels of IFN $\gamma$, CIITA is retained in the cytosol of MSCs, thereby controlling the cells' ability to function as antigen presenting cells [6]. The significance of this finding is the protective effects of MSCs in bone marrow. Exacerbated inflammation could lead to bone marrow suppression [7]. Thus, ideally, it would be desirable to rapidly clear insult to the bone marrow by infectious agents, without overt inflammation. In this regard, the location of MSCs around blood vessels provides them with opportunities to rapidly clear infections mostly due to their properties of antigen presenting cells [5]. In response to antigen presentation by MSCs, immune cells are expected to produce proinflammatory cytokines, including IFN $\gamma$. At high levels of IFN $\gamma$, MHC-II expression is downregulated [5], which should coincide with the MSCs transitioning from immune stimulators to suppressors. Insights into this mechanism are presented by Sheng et al., in this issue [8].

Sheng et al. describe a role for the expressions of $\mathrm{B} 7-\mathrm{H} 1$ on the MSCs. B7-H1 (CD274) elicits both immunostimulatory and inhibitory immune responses [9]. The authors have linked previous reports for IFN $\gamma$ as a negative regulator of immune stimulation by MSCs $[5,6,10]$. In a setting of activated T-cells, the study showed upregulation of B7-H1 by T cell-mediated production of IFN $\gamma$. Further knockdown studies and replacement of IFN $\gamma$ verified the relevance of B7-H1 to the immune suppressor properties of MSCs.

The study by Sheng et al. is important to further understanding the mechanism by which IFN $\gamma$ could be central to the immune suppressive properties of MSCs. The key findings are summarized in Figure 1. Shown is a human MSC with the expression of MHC-II. Upon exposure to insult, such as bacterial infection, the MHC-II molecules facilitate the antigen presenting properties of MSCs, which lead to the activation of T-cells. The latter cells produce IFN $\gamma$. At high levels, IFN $\gamma$ mediates decreased expression of MHC-II to switch off the antigen presentation capability. Concomitant with decreased MHC-II expression is the upregulation of B7-H1, which mediates inhibitor effects on activated T-cells. In summary, the work by Sheng et al. introduces a novel mechanism by which activated T-cells negatively affect the immune stimulatory properties of MSCs. Future studies on the involvement of cytokines and effects on the master regulator of MHC-II, CIITA, will begin translation of MSCs closer to the clinic.

The immune properties of MSCs are significant to regenerative medicine where it would be imperative to take MSCs off the shelf from allogeneic sources. An understanding of balances among the immune stimulatory, inhibitory properties and the ability of MSCs to form specialized cells are important for future clinical applications in regenerative medicine, and also in immunemediated disorders.

\section{References}

1 Castillo M, Liu K, Bonilla L, Rameshwar P. The immune properties of mesenchymal stem cells. Intl J Biomed Sci 2007; 3:100-104. 


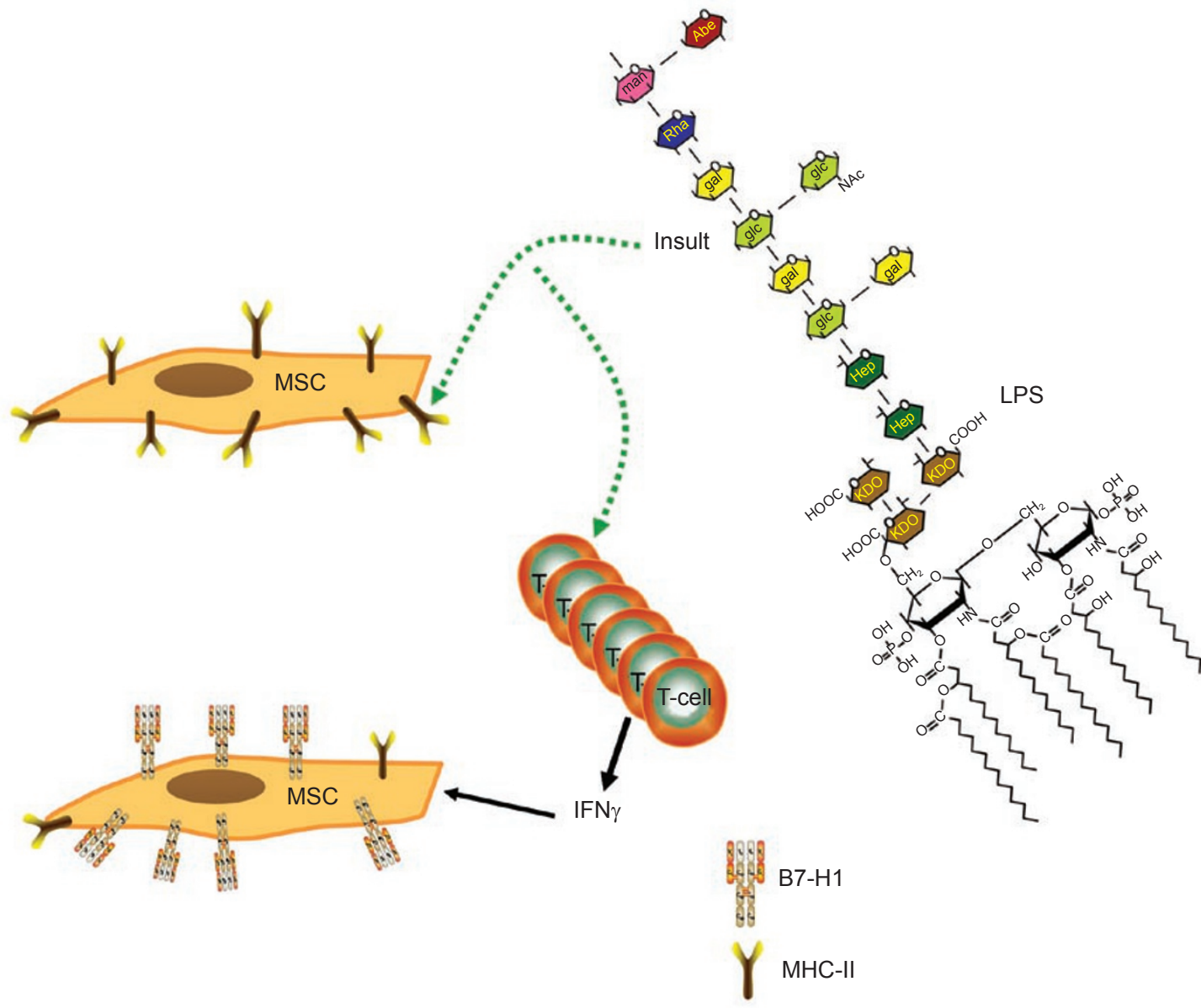

Figure $1 \mathrm{~A}$ resting MSC is shown with the expression of MHC-II (top left). Upon exposure to bacterial infection (or other insult) the MSC acts as an antigen presenting cell and activates T-cells. The T-cells produce IFN $\gamma$. In the presence of IFN $\gamma$, MHC-II expression is decreased with concomitant increase in the expression of the inhibitory B7-H1.

2 Bianco P, Riminucci M, Gronthos S, Robey PG. Bone marrow stromal stem cells: Nature, biology, and potential applications. Stem Cells 2001; 19:180192.

3 Caplan AI, Bruder SP. Mesenchymal stem cells: building blocks for molecular medicine in the 21 st century. Trends in Mol Med 2001; 7:259-264.

4 Patel SA, Sherman L, Munoz J, Rameshwar P. Immunological properties of mesenchymal stem cells and clinical implications. Arch Immunol Ther Exp 2008; 56:1-8.

5 Chan JL, Tang KC, Patel AP, et al. An- tigen-presenting property of mesenchymal stem cells occurs during a narrow window at low levels of interferongamma. Blood 2006; 107:4817-4824.

6 Tang KC, Trzaska KA, Smirnov SV, et al. Down-Regulation of MHC II in Mesenchymal Stem Cells at High IFN\{gamma\} Can Be Partly Explained by Cytoplasmic Retention of CIITA. J Immunol 2008; 180:1826-1833.

7 Nishikawa SI, Hashi H, Honda K, Fraser $\mathrm{S}$, Yoshida H. Inflammation, a prototype for organogenesis of the lymphopoietic/hematopoietic system. Curr Opin Immunol 2000; 12:342-345.
8 Sheng H, Wang Y, Jin Y-Q, et al. A critical role of IFN gamma in priming MSC-mediated suppression of $\mathrm{T}$ cell proliferation through up-regulation of B7-H1. Cell Res 2008; 18:846-857.

9 Dong $\mathrm{H}$, Chen X. Immunoregulatory role of B7-H1 in chronicity of inflammatory responses. Cell Mol Immunol 2006; 3:179-187.

10 Stagg J, Pommey S, Eliopoulos N, Galipeau J. Interferon-gamma-stimulated marrow stromal cells: a new type of nonhematopoietic antigen-presenting cell. Blood 2006; 107:2570-2577. 